\title{
Proton NMR Study of Molecular Dynamics and Phase Transitions in Trimethyl Ammonium Hexachloro Plumbate $\left[\mathrm{NH}\left(\mathrm{CH}_{3}\right)_{3}\right]_{2} \mathrm{PbCl}_{6}$ and Tetramethyl Ammonium Hexachloro Plumbate $\left[\mathbf{N}\left(\mathrm{CH}_{3}\right)_{4}\right]_{2} \mathbf{P b C l}_{6}$
}

\author{
B.V.S. MuRThY, K.P. RAMESH, and J. RAMAKRISHNA ${ }^{1}$ ) \\ Department of Physics, Indian Institute of Science, Bangalore 560 012, India
}

\begin{abstract}
The proton spin-lattice relaxation time $\left(T_{1}\right)$ measured as a function of temperature in the range 424 to $119 \mathrm{~K}$ in trimethyl ammonium hexachloro plumbate $\left[(\mathrm{TrMA})_{2} \mathrm{PbCl}_{6}\right]$ shows phase transitions at 340 and $119 \mathrm{~K}$. The observed badly resolved minima in this compound are explained on the basis of $C_{3}$ reorientations of inequivalent trimethyl ammonium and methyl groups. The computed second moment values, suggest the freezing of both types of reorientation around $117 \mathrm{~K}$. Proton $T_{1}$ studies in tetramethyl ammonium hexachloro plumbate [(TMA $\left.)_{2} \mathrm{PbCl}_{6}\right]$ in the temperature range 295 to $106 \mathrm{~K}$ shows a deep $T_{1}$ minimum at $180 \mathrm{~K}$ and a shallow one around $111 \mathrm{~K}$, which are interpreted in terms of inequivalent tetramethyl ammonium (TMA) ions as well as $\mathrm{CH}_{3}$ reorientation.
\end{abstract}

\section{Introduction}

${ }^{1} \mathrm{H}$ NMR spin-lattice relaxation study of the dynamics of the trimethyl ammonium (TrMA) ion has been carried out only in a few simple compounds like TrMA halides [1 to 4] and TrMA oxalates [5] and it was observed that the relaxation is dominated by reorientations of the TrMA ion in the high temperature range $(>150 \mathrm{~K})$, while at lower temperatures it is dominated by the dynamics of the methyl groups. As the correlation times for these motions are close to each other in these simple compounds, the observed spinlattice relaxation $T_{1}$ minima are not resolved in the TrMA halides while they are barely resolved in the other compounds. On the other hand, the $T_{1}$ minima in the TrMA hexahalo metallates of the $\mathrm{R}_{2} \mathrm{MX}_{6}$ family $(\mathrm{R}=\mathrm{TrMA}, \mathrm{M}=\mathrm{Pt}, \mathrm{Sn}, \mathrm{Te}$ and $\mathrm{X}=\mathrm{Cl}, \mathrm{Br}$ and $\mathrm{I}$ ) are well resolved [6]. The NMR study in TrMA hexabromo selenate has revealed the presence of inequivalent TrMA ions and methyl groups [7]. Jagadeesh et al. [8] have reported the presence of inequivalent TrMA ions and methyl groups in the ( $\operatorname{TrMA})_{3} \mathrm{Sb}_{2} \mathrm{Cl}_{9}$. The activation energies for the TrMA ion and the methyl groups in the TrMA compounds of $\mathrm{R}_{2} \mathrm{MX}_{6}$ family $(\approx 29.3$ and $\approx 14.6 \mathrm{~kJ} / \mathrm{mol})[6]$ are smaller than the corresponding values in the TrMA halides and in $\operatorname{TrMA}$ oxalates $(\approx 37.7$ and $\approx 20.9 \mathrm{~kJ} / \mathrm{mol})$ [1 to 4]. While (TrMA) halides have shown phase transitions [1 to 4], the ( $\operatorname{TrMA})_{2} \mathrm{MX}_{6}$ type compounds investigated so far $[6,7]$ have not exhibited any phase transitions. The TrMA ion has only a threefold symmetry axis, whereas the tetramethyl ammonium (TMA) ion has much greater symmetry (four threefold axes, three twofold axes) and TMA based $\mathrm{R}_{2} \mathrm{MX}_{6}$ type

1) Author for correspondence. 
compounds often exhibit phase transitions [9, 10]. It would be interesting to study the effect of this higher symmetry on the proton dynamics. Moreover, many compounds of the $\mathrm{RMX}_{3}$ family with $\mathrm{R}=$ methyl ammonium or TMA, $\mathrm{M}=\mathrm{Pb}$ and $(\mathrm{X}=\mathrm{Cl}, \mathrm{Br}$ and $\mathrm{I})$ have shown phase transitions $[11,12]$. Hence, it would be interesting to study the lead containing systems with TrMA and TMA cations. We have therefore measured ${ }^{1} \mathrm{H}$ NMR spin-lattice relaxation time as a function of temperature in $(\operatorname{Tr} M A)_{2} \mathrm{PbCl}_{6}$ as well as (TMA) ${ }_{2} \mathrm{PbCl}_{6}$ and the results are reported here.

The method of preparation and powder X-ray diffraction study of the (TrMA) ${ }_{2} \mathrm{PbCl}_{6}$ as well as that of the (TMA) ${ }_{2} \mathrm{PbCl}_{6}$ are reported by Brill and Welsh [13] and the DTA studies are reported by Blazejowski and Szychlinski [14]. Both the compounds are prepared by the reaction of a solution of lead acetate in concentrated hydrochloric acid with a solution of the corresponding cation chloride in concentrated hydrochloric acid. The crystals are obtained by passing chlorine gas and cooling the solution to $0{ }^{\circ} \mathrm{C}$. They are cubic with space group Fm3m and isostructural with TrMA hexachloro stannate and tellurate [13]. We have characterised our samples by X-ray diffraction, IR and elemental analysis of lead. The $d$ spacings recorded in our compounds compare well with those reported for the $\mathrm{R}_{2} \mathrm{MX}_{6}$ family by Brill and Welsh [13] and others $[15,16]$. The IR frequencies recorded in the range 400 to $4000 \mathrm{~cm}^{-1}$ agree with the corresponding values reported by Stammler [17] for the TrMA and TMA halides. The elemental analysis of lead yields a value of $38.0 \%$ against the estimated $38.4 \%$ for (TrMA) $)_{2} \mathrm{PbCl}_{6}$ and $36.4 \%$ against a value of $36.4 \%$ for (TMA) ${ }_{2} \mathrm{PbCl}_{6}$.

We have carried out NMR measurements $\left(T_{1}\right.$ and $\left.M_{2}\right)$ in the temperature range 110 to $424 \mathrm{~K}$ using a home-made spectrometer working at $10 \mathrm{MHz}$. The temperature of the sample, in the range 300 to $110 \mathrm{~K}$, is varied using a gas flow arrangement while the range from 424 to $300 \mathrm{~K}$ is covered with a heating arrangement and the sample temperature is measured using a copper-constantan thermocouple to an accuracy of $\pm 0.5 \mathrm{~K}$.

\section{Results and Discussion}

\subsection{Trimethyl ammonium hexachloro plumbate $\left[\mathrm{NH}\left(\mathrm{CH}_{3}\right)_{3}\right]_{2} \mathrm{PbCl}_{6}$}

\subsubsection{Relaxation}

The ${ }^{1} \mathrm{H}$ relaxation time $\left(T_{1}\right)$ was measured from 424 to $117.5 \mathrm{~K}$. A plot of $T_{1}$ versus $1000 / T$ is shown in Fig. 1. The relaxation time decreases rapidly from 424 down to $180 \mathrm{~K}$, where two badly resolved minima $(5.6 \mathrm{~ms}$ at $176 \mathrm{~K}$ and $6.0 \mathrm{~ms}$ at $164 \mathrm{~K})$ are observed. In this temperature range ( 424 to $180 \mathrm{~K}$ ) small changes in the slope are observed at 340 and $226 \mathrm{~K}$. In the low temperature region, below $164 \mathrm{~K}$, the relaxation time increases and shows a discontinuous jump at $119 \mathrm{~K}$. The signal could not be observed below $117 \mathrm{~K}$.

The $T_{1}$ behaviour is analysed using the model developed by Sjöblom and Punkkinen [3]. They have considered the modulation of the proton-proton interactions by the reorientation of the methyl groups and the TrMA ions about their $C_{3}$ axes. The intra-methyl, inter-methyl and methyl proton-lone proton pairwise interactions are considered in this model. The expression for the effective relaxation rate is given by the equation

$$
T_{1}^{-1}=\frac{9}{20 \hbar^{2}} \sum_{\mu=1}^{2}\left[\sum_{i=1}^{3} K_{i}^{(\mu)} \frac{k_{i}}{k_{i}^{2}+(\mu \omega)^{2}}+\sum_{j=1}^{5} L_{j}^{(\mu)} \frac{k_{j}}{k_{j}^{2}+(\mu \omega)^{2}}+\sum_{n=1}^{3} M_{n}^{(\mu)} \frac{k_{n}}{k_{n}^{2}+(\mu \omega)^{2}}\right]
$$

with $k_{1}=r, k_{2}=r+R, k_{3}=R, k_{4}=2 r$ and $k_{5}=2 r+R$. 


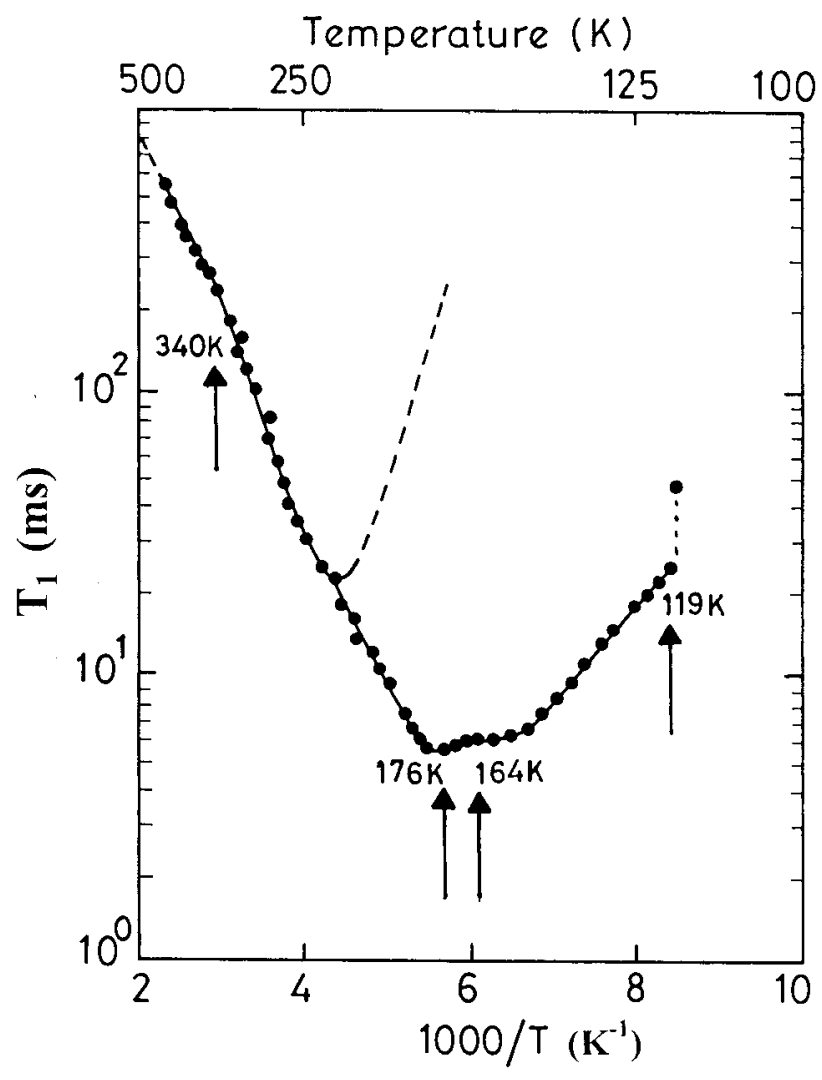

Fig. 1. Plot of relaxation time $T_{1}$ vs. $1000 / T$ in $\left[\mathrm{NH}\left(\mathrm{CH}_{3}\right)_{3}\right]_{2} \mathrm{PbCl}_{6}$

Here $r=\tau_{\mathrm{c}}^{-1}$ is the correlation rate for reorientations of the methyl groups and $R=\tau_{\mathrm{T}}^{-1}$, is the correlation rate for reorientations of the TrMA ion. The temperature variation of the correlation times $(\tau)$ is given by the Arrhenius equation

$\tau=\tau_{0} \exp \left(E_{\mathrm{a}} / k T\right)$,

where $E_{\mathrm{a}}$ is the activation energy for the type of motion considered. The values $K_{i}^{(\mu)}$, $L_{j}^{(u)}, M_{n}^{(u)}$ which are used for the $T_{1}$ analysis [3] are given in Table 1.

The $T_{1}$ behaviour above $340 \mathrm{~K}$ is attributed to the $C_{3}$ reorientation of the TrMA ion. The observed $T_{1}$ values follow the equation (1) yielding an activation energy of $12.4 \mathrm{~kJ} /$ mol and a pre-exponential factor of $2.9 \times 10^{-12} \mathrm{~s}$. This activation energy is smaller than the value of $25.1 \mathrm{~kJ} / \mathrm{mol}$ observed in TrMA hexahalo metallates of the $\mathrm{R}_{2} \mathrm{MX}_{6}$ family

Table 1

The relaxation constants $K_{i}^{(\mu)}, M_{n}^{(\mu)}$ and $L_{j}^{(\mu)}\left(\right.$ in $10^{8} \mathrm{~s}^{-2}$ ) for the trimethyl ammonium ion

\begin{tabular}{lllll}
\hline$\mu$ & $i, j, n$ & $\begin{array}{l}K_{i}^{(\mu)} \\
\text { (intramethyl) }\end{array}$ & $\begin{array}{l}M_{n}^{(\mu)} \\
\text { (lone proton) }\end{array}$ & $\begin{array}{l}L_{j}^{(\mu)} \\
\text { (intermethyl) }\end{array}$ \\
\hline 1 & 1 & 24.22 & 1.74 & 0.63 \\
& 2 & 48.45 & 7.28 & 4.30 \\
& 3 & 19.99 & 11.68 & 6.86 \\
& 4 & & & 1.16 \\
& 5 & & & 2.39 \\
& & & 6.83 & 2.56 \\
& 1 & 94.84 & 29.49 & 17.29 \\
& 2 & 193.08 & 46.65 & 28.16 \\
& 3 & 81.22 & & 4.58 \\
& 4 & & & 9.78 \\
\hline
\end{tabular}


$(\mathrm{M}=\mathrm{Pt}, \mathrm{Sn}$, Te and $\mathrm{X}=\mathrm{Cl}, \mathrm{Br})[6]$ and 28.9 and $24.3 \mathrm{~kJ} / \mathrm{mol}$ found in TrMA hexabromo selenate for the $C_{3}$ reorientation of TrMA ion [7]. The pre-exponential factors for the $C_{3}$ reorientation of the two inequivalent TrMA ions in $(\operatorname{TrMA})_{2} \mathrm{MX}_{6}(\mathrm{M}=\mathrm{Pt}, \mathrm{Sn}$, $\mathrm{Te}$ and $\mathrm{X}=\mathrm{Cl}, \mathrm{Br})[6]$ and in $\left(\mathrm{TrMA}_{2} \mathrm{SeBr}_{6}\right.$ are $(0.6$ to 3$) \times 10^{-13} \mathrm{~s}$ and (3.8 to 4.0) $\times 10^{-14} \mathrm{~s}$, respectively. The smaller activation energy for the reorientation of the TrMA ion indicates a greater mobility in the present compound. The slope change at $340 \mathrm{~K}$ could be due to a phase transition. However, it needs to be confirmed by other measurements.

The $T_{1}$ behaviour in phase II (340 to $119 \mathrm{~K}$ ), could be explained in terms of inequivalent TrMA ions and inequivalent methyl groups. In the presence of inequivalent molecular groups, the resultant relaxation rate is given by [18]

$$
T_{1}^{-1}=\frac{\left[N_{\mathrm{a}} T_{1 \mathrm{a}}^{-1}+N_{\mathrm{b}} T_{1 \mathrm{~b}}^{-1}\right]}{\left(N_{\mathrm{a}}+N_{\mathrm{b}}\right)},
$$

where $N_{\mathrm{a}}$ and $N_{\mathrm{b}}$ are the numbers of a and b type TrMA ions with the corresponding relaxation times $T_{1 \mathrm{a}}$ and $T_{1 \mathrm{~b}}$, respectively, given by equation (1). A small change in slope, around $226 \mathrm{~K}$, indicates a possible $T_{1}$ minimum (of $22 \mathrm{~ms}$ ), occurring at this temperature. This $T_{1}$ minimum is twice the expected value $(\approx 11 \mathrm{~ms}$ at $10 \mathrm{MHz})$ for the reorientation of the TrMA ion while the barely resolved minima (5.6 and $6.0 \mathrm{~ms}$ ) observed at 176 and $164 \mathrm{~K}$, are also longer than the expected $(5.5 \mathrm{~ms})$ values for the reorientation of the methyl group. The poorly resolved minimum $(22 \mathrm{~ms})$ on the high temperature side is explained in terms of the contributions from the two inequivalent TrMA ions, while the barely resolved minima of 5.6 and $6.0 \mathrm{~ms}$ are explained in terms of contributions from the inequivalent methyl groups. The slope of the linear portion on either side of the $T_{1 \min }$ is used to obtain the approximate values of $E_{\mathrm{a}}$ (activation energy) and $\tau_{0}$ (pre-exponential factor). These $E_{\mathrm{a}}$ and $\tau_{0}$ values are used as initial parameters in equations (1), (2) and (3) and are iterated to get the best fit values. We have used the non-linear last square (NLS) fitting programme in the sigma plot for our calculations. The best fit of the observed $T_{1}$ values to the equations (1), (2) and (3) yield activation energies of 14.5 and $16.8 \mathrm{~kJ} / \mathrm{mol}$ for the TrMA ion dynamics. The preexponential factors $\left(1.6 \times 10^{-13}\right.$ and $\left.4.1 \times 10^{-13} \mathrm{~s}\right)$ for the a and $\mathrm{b}$ type of TrMA ions in phase II $(340$ to $119 \mathrm{~K})$ are comparable to those $(0.6$ to 3.0$) \times 10^{-13}$ s observed in the

Table 2

Activation energy and pre-exponential factors in trimethyl ammonium hexachloro plumbate

\begin{tabular}{|c|c|c|c|c|}
\hline & $T(K)$ & $\begin{array}{l}E_{\mathrm{a}} \\
(\mathrm{kJ} / \mathrm{mol})\end{array}$ & $\begin{array}{l}\tau_{0} \\
(\mathrm{~s})\end{array}$ & motion \\
\hline phase I & 424 to 340 & $12.4 \pm 0.6$ & $(2.9 \pm 0.2) \times 10^{-12}$ & $C_{3}$ of TrMA ion \\
\hline phase II & $\begin{array}{l}340 \text { to } 119 \\
\text { type a TrMA } \\
\mathrm{CH}_{3} \\
\text { type b TrMA } \\
\mathrm{CH}_{3}\end{array}$ & $\begin{aligned} 14.5 & \pm 0.7 \\
8.3 & \pm 0.4 \\
16.8 & \pm 0.8 \\
10.7 & \pm 0.5\end{aligned}$ & $\begin{array}{l}(1.6 \pm 0.1) \times 10^{-13} \\
(2.9 \pm 0.2) \times 10^{-13} \\
(4.1 \pm 0.2) \times 10^{-13} \\
(1.9 \pm 0.1) \times 10^{-12}\end{array}$ & $\begin{array}{l}C_{3} \text { of } \mathrm{TrMA} \text { ion } \\
C_{3} \text { of } \mathrm{CH}_{3} \text { group } \\
C_{3} \text { of } \mathrm{TrMA} \text { ion } \\
C_{3} \text { of } \mathrm{CH}_{3} \text { group }\end{array}$ \\
\hline phase III & $<119$ & $\begin{array}{l}- \\
-\end{array}$ & $\begin{array}{l}\text { no signal } \\
\text { below } 117 \mathrm{~K}\end{array}$ & $\begin{array}{l}\text { frozen on NMR } \\
\text { time scale }\end{array}$ \\
\hline
\end{tabular}


other TrMA compounds of the $\mathrm{R}_{2} \mathrm{MX}_{6}$ family [6]. Similarly, the activation energies and the pre-exponential factors for the inequivalent methyl groups are $8.3 \mathrm{~kJ} / \mathrm{mol}$, $2.9 \times 10^{-13} \mathrm{~s}$ (for type a methyl groups) and $10.7 \mathrm{~kJ} / \mathrm{mol}, 1.9 \times 10^{-12} \mathrm{~s}$ (for type $\mathrm{b}$ methyl groups). The motional parameters for the TrMA ions and methyl groups in different phases of this compound are given in Table 2. The activation energy reported by Ikeda et al. [6] for the $C_{3}$ reorientation of the methyl groups in the TrMA compounds of the $\mathrm{R}_{2} \mathrm{MX}_{6}$ family $(\mathrm{M}=\mathrm{Pt}, \mathrm{Sn}$, Te and $\mathrm{X}=\mathrm{Cl}, \mathrm{Br})$, is $\approx 12.6 \mathrm{~kJ} / \mathrm{mol}$ and the pre-exponential factor is $(4$ to 8$) \times 10^{-13} \mathrm{~s}$. In the present compound, the activation energies and the pre-exponential factors are comparable to those observed in other (TrMA $)_{2} \mathrm{MX}_{6}$ compounds.

The discontinuous jump in $T_{1}$ at $\approx 119 \mathrm{~K}$ can be attributed to a phase transition. More points below $119 \mathrm{~K}$ would have made it more convincing. However, it was not possible as the signal could not be observed below that temperature. An independent confirmation by other measurements is thus necessary. Though discontinuous jumps in $T_{1}$ values, indicating phase transitions, are reported in TrMA chloride [2] and trimethylamine gallane [19], such phase transitions are not reported in TrMA hexahalo metallates $[6,7]$ so far. This appears to be the first report of a phase transition in TrMA compounds of the $\mathrm{R}_{2} \mathrm{MX}_{6}$ family.

A comparative study of the ${ }^{1} \mathrm{H}$ NMR results of this compound with those of the other TrMA hexahalo metallates, indicates greater mobility (lower $E_{\mathrm{a}}$ values) for the TrMA ion in the present compound.

\subsubsection{Second moment}

The second moment, computed from the absorption line obtained by Fourier transforming the free induction decay (FID), remains constant at $2.6 \mathrm{G}^{2}$ from 424 to $160 \mathrm{~K}$ (Fig. 2). On further cooling it increases rapidly and reaches $\approx 26 \mathrm{G}^{2}$ around $117 \mathrm{~K}$.

The theoretical second moment, calculated from the geometry of the rigid TrMA ion, by Andrew and Canepa [20] is $29.4 \mathrm{G}^{2}$. In TrMA chloride the second moment in the presence of rapid methyl reorientation alone is $9.9 \mathrm{G}^{2}$ and when both the TrMA ion

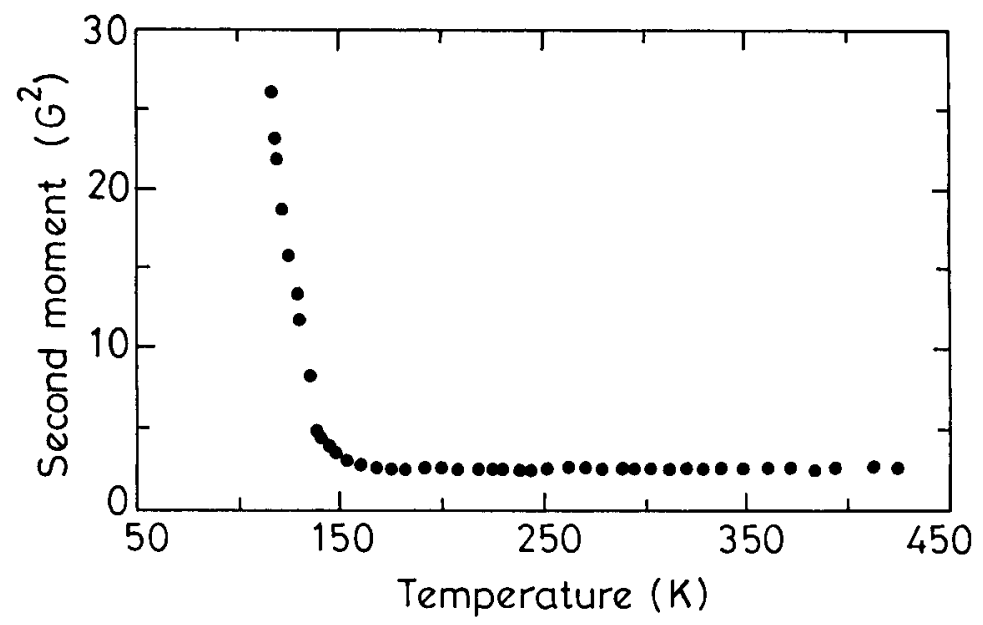

Fig. 2. Plot of second moment $M_{2}$ vs. temperature in $\left[\mathrm{NH}\left(\mathrm{CH}_{3}\right)_{3}\right]_{2} \mathrm{PbCl}_{6}$ 
and the methyl groups are undergoing rapid reorientations, it is $2.3 \mathrm{G}^{2}$ [20]. The second moment study in (TrMA) ${ }_{2} \mathrm{MCl}_{6}(\mathrm{M}=\mathrm{Pt}, \mathrm{Sn})$ and $\left(\operatorname{TrMA}_{2} \mathrm{PtBr}_{6}\right.$ by Ikeda et al. [6] shows a steady value of $\approx 2.0 \mathrm{G}^{2}$ in the temperature range 400 to $180 \mathrm{~K}$, followed by second moment transitions from 2.0 to $10 \mathrm{G}^{2}$ at $180 \mathrm{~K}$ and from 10 to $27.5 \mathrm{G}^{2}$ at $130 \mathrm{~K}$. The high temperature value of $2.0 \mathrm{G}^{2}$ is attributed to the reorientation of both TrMA ion and the methyl groups about their $C_{3}$ axes [6]. The increase in second moment at $180 \mathrm{~K}$ from 2.0 to $10 \mathrm{G}^{2}$ is attributed to the freezing of the TrMA ion and the subsequent increase in second moment from 10 to $27.5 \mathrm{G}^{2}$ at $130 \mathrm{~K}$ indicates the freezing of methyl group reorientation. The increase in the second moment in this compound from 2.6 to $26 \mathrm{G}^{2}$ indicates the freezing of both TrMA ion and methyl group motions within a narrow temperature range and this accounts for the loss of the FID below $117 \mathrm{~K}$.

\subsection{Tetramethyl ammonium hexachloro plumbate $\left[\mathrm{N}\left(\mathrm{CH}_{3}\right)_{4}\right]_{2} \mathrm{PbCl}_{6}$}

\subsubsection{Relaxation}

A plot of ${ }^{1} \mathrm{H}$ spin-lattice relaxation time $\left(T_{1}\right)$ measured from 295 to $106 \mathrm{~K}$ at $10 \mathrm{MHz}$, is shown in Fig. 3. The relaxation behaviour is BPP like with two $T_{1}$ minima, one of $4.0 \mathrm{~ms}$ around $180 \mathrm{~K}$ and the other of $14.5 \mathrm{~ms}$ around $111 \mathrm{~K}$. The signal could not be observed below $106 \mathrm{~K}$. We have, after completing this work, come across a paper by

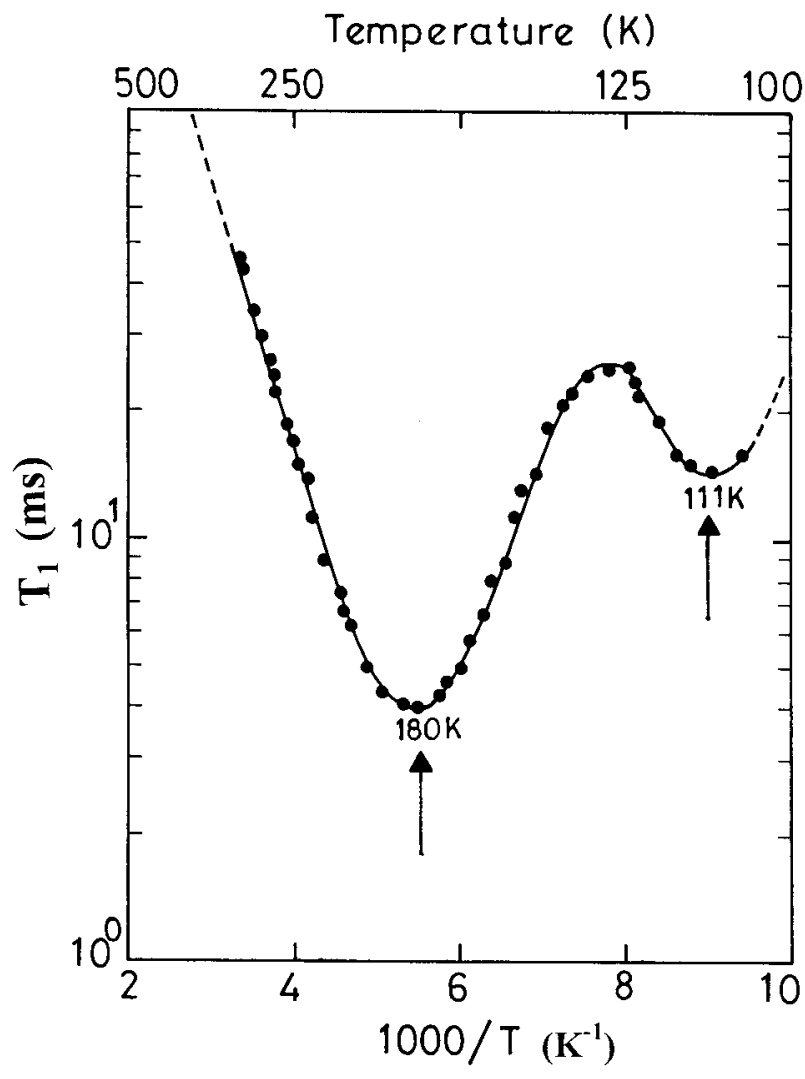

Fig. 3. Plot of relaxation time $T_{1}$ vs. $1000 / T$ in $\left[\mathrm{N}\left(\mathrm{CH}_{3}\right)_{4}\right]_{2} \mathrm{PbCl}_{6}$ 
Furukawa et al. [21] on NMR/NQR study of (TMA) ${ }_{2} \mathrm{PbCl}_{6}$. They have measured the ${ }^{1} \mathrm{H}$ spin-lattice relaxation time at $20 \mathrm{MHz}$ and observed two $T_{1}$ minima. However, they have reported a hysteresis of about $20 \mathrm{~K}$ around $110 \mathrm{~K}$, in the proton $T_{1}$ behaviour which was not seen by them in the halogen NQR. Our $T_{1}$ minima at $10 \mathrm{MHz}$ and their $T_{1}$ minima at $20 \mathrm{MHz}$ are as expected from the Bloembergen, Purcell, and Pound (BPP) theory.

The $T_{1}$ behaviour due to TMA dynamics can be expressed as, following the modified BPP model [22],

$$
T_{1}^{-1}=A g\left(\omega, \tau_{\mathrm{c}_{2}}\right)+B g\left(\omega, \tau_{\mathrm{c}_{1}}\right)
$$

where

$$
\begin{aligned}
& A=\frac{9}{20} \frac{\gamma^{4} \hbar^{2}}{r^{6}}, \\
& B=\frac{3}{20} \frac{\gamma^{4} \hbar^{2}}{r^{6}}+\frac{27}{10} \frac{\gamma^{4} \hbar^{2}}{R^{6}}, \\
& \frac{1}{\tau_{\mathrm{c} 2}}=\frac{1}{\tau_{\mathrm{c}}}+\frac{1}{\tau_{\mathrm{c} 1}},
\end{aligned}
$$

$r$ is the interproton distance in a methyl group $(0.178 \mathrm{~nm})$ and $R$ the intermethyl distance $(0.304 \mathrm{~nm})$ [22]. The model predicts two $T_{1}$ minima, one due to TMA motion (at a higher temperature) and the other due to $\mathrm{CH}_{3}$ dynamics (at a lower temperature); the values being 9.8 and $5.5 \mathrm{~ms}$ at $10 \mathrm{MHz}$, respectively.

Furukawa et al. [21] have attributed the two $T_{1}$ minima to inequivalent TMA ions in the ratio 3:1 with activation energies 19.1 and $8.3 \mathrm{~kJ} / \mathrm{mol}$. The activation energies for the two inequivalent TMA ions, obtained by them are thus widely different. Similarly, the two $T_{1}$ minimum values are also widely different.

We have reconsidered the $T_{1}$ behaviour in (TMA) ${ }_{2} \mathrm{PbCl}_{6}$. The experimental $T_{1}$ minimum of $4.0 \mathrm{~ms}$ observed at $180 \mathrm{~K}$ is much shorter than the expected value of $9.8 \mathrm{~ms}$ (10 MHz) for TMA tumbling. The observed $T_{1}$ behaviour could be explained to a large extent, assuming the presence of two inequivalent TMA ions (type a and type b) in the ratio of 1:1 using equation (4) and an equation similar to equation (3). But, a descrepancy between the experimental and calculated $T_{1}$ values is found, which could not be adjusted by assuming inequivalent methyl groups. Hence, small angle torsion of the methyl groups is considered as an additional relaxation mechanism. The relaxation rate due to this is given by

$$
T_{1}^{-1}=(9 / 40) \gamma^{4} \hbar^{2} r^{-6}(1-\cos 2 \theta) g(\omega, \tau),
$$

where $\tau$ is the correlation time for small angle torsional oscillations of the methyl groups and $\mathrm{r}$ is the interproton distance in the methyl group and $\theta$ is the amplitude of torsional oscillations. The best fit parameters with these mechanisms are given in Table 3. The activation energies for the TMA ions and the $\mathrm{CH}_{3}$ groups are not widely different and consequently, the $T_{1}$ minima due to the different motions are not resolved. The high temperature minimum $(180 \mathrm{~K})$ is ascribed to the combined effect of these two motions. The small angle torsional oscillation of the methyl group explains the shallow $T_{1}$ minimum observed at $111 \mathrm{~K}$. Such mechanism has been considered by Prabhumirashi et al. [27] to explain the shallow $T_{1}$ minimum of protons at low tempera- 
Table 3

Activation energy and pre-exponential factors in tetramethyl ammonium hexachloro plumbate

\begin{tabular}{lll}
\hline $\begin{array}{l}E_{\mathrm{a}} \\
(\mathrm{kJ} / \mathrm{mol})\end{array}$ & $\begin{array}{l}\tau_{0} \\
(\mathrm{~s})\end{array}$ & motion \\
\hline $15.9 \pm 0.8$ & $(6.2 \pm 0.3) \times 10^{-13}$ & type a TMA tumbling \\
$15.1 \pm 0.7$ & $(3.2 \pm 0.2) \times 10^{-13}$ & type b TMA tumbling \\
$10.0 \pm 0.5$ & $(2.4 \pm 0.1) \times 10^{-13}$ & $\mathrm{C}_{3}$ reorientation of $\mathrm{CH}_{3}$ \\
$12.1 \pm 0.6$ & $(4.7 \pm 0.3) \times 10^{-14}$ & small angle torsion of $\mathrm{CH}_{3}$ \\
\hline
\end{tabular}

tures in $(\mathrm{TMA})_{2} \mathrm{MCl}_{6}(\mathrm{M}=\mathrm{Pt}, \mathrm{Sn}, \mathrm{Te})$ compounds. The amplitude of the methyl torsion $\left(14^{\circ}\right)$ compares well with the values reported by Berg [23], Berg and Sotofte [24] and van der Ohe $[25,26]$. Also, it is in agreement with the value reported by Prabhumirashi et al. [27], in (TMA $)_{2} \mathrm{MCl}_{6}(\mathrm{M}=\mathrm{Pt}, \mathrm{Sn}, \mathrm{Te})$ compounds.

The FID in (TMA) ${ }_{2} \mathrm{PbCl}_{6}$ could not be observed below $106 \mathrm{~K}$. A change in IR and Raman frequencies is also observed in this compound around $106 \mathrm{~K}$ [28], which is ascribed to a change in the motional mode of the methyl groups. Further investigation is necessary to confirm if a phase change is taking place.

\subsubsection{Second moment}

The temperature dependence of the second moment, shows a nearly constant value of $0.55 \mathrm{G}^{2}$ from 297 to $160 \mathrm{~K}$ (Fig. 4). A second moment transition from 0.6 to $9.3 \mathrm{G}^{2}$ is observed around $125 \mathrm{~K}$. The constant value of the second moment $\left(0.6 \mathrm{G}^{2}\right)$ is attributed to the motional narrowing due to the reorientation of the methyl groups and the overall tumbling of the TMA ions in the temperature range larger than $125 \mathrm{~K}$. Below this temperature, the freezing of TMA tumbling gives rise to an increase in the observed value of the second moment to $9.3 \mathrm{G}^{2}$ and shows the presence of methyl group motion.

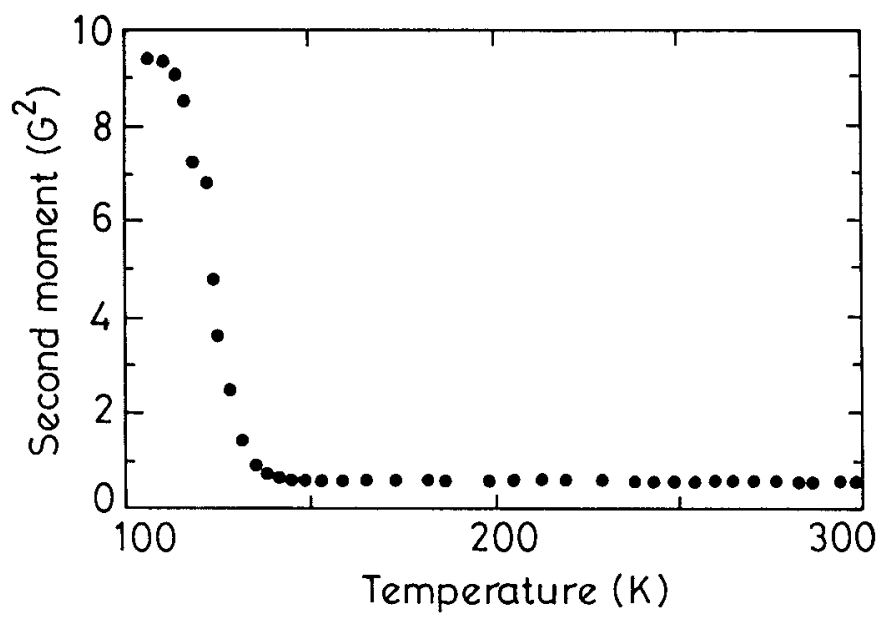

Fig. 4. Plot of second moment $M_{2}$ vs. temperature in $\left[\mathrm{N}\left(\mathrm{CH}_{3}\right)_{4}\right]_{2} \mathrm{PbCl}_{6}$ 
The studies of the temperature dependence of second moment by Andrew and Canepa [20] in TMACl and by Ludin and Zeer [29] in $\mathrm{TMAHgX}_{3}(\mathrm{X}=\mathrm{Cl}, \mathrm{Br})$ compounds show a constant value of 1.5 and $0.6 \mathrm{G}^{2}$, respectively, in the temperature range larger than $150 \mathrm{~K}$. Below this temperature the second moment increases steadily and reaches values of 33.6 and $24 \mathrm{G}^{2}$ around $77 \mathrm{~K}$. The freezing of TMA tumbling around $150 \mathrm{~K}$ and the reduction in the efficiency of the $C_{3}$ reorientation of the methyl groups in the TMA ion are given as the reasons for the above observations.

Prabhumirashi et al. [27] report a rigid lattice value of $29 \mathrm{G}^{2}$ in (TMA) ${ }_{2} \mathrm{MX}_{6}$ compounds having $\mathrm{Pt}, \mathrm{Sn}$ and $\mathrm{Te}$ as the metal atoms. The second moment observed in these compounds, due to the simultaneous presence of TMA tumbling and methyl group reorientation is $0.9 \mathrm{G}^{2}$, while that in the presence of methyl group motion alone is $9.0 \mathrm{G}^{2}$. In the present compound, the second moment value of $9.3 \mathrm{G}^{2}$, below $125 \mathrm{~K}$, is in agreement with the value reported for the methyl group motion in the compounds of the $\mathrm{R}_{2} \mathrm{MX}_{6}$ family [10, 27].

Acknowledgements The financial support from Department of Atomic Energy, Government of India is gratefully acknowledged. One of the authors (B.V.S.M.) would like to thank S.J. College of Engineering, Mysore for leave of absence under the QIP programme.

\section{References}

[1] R. SuöBlom and J. Tegenfeldt, Acta Chem. Scand. 26, 3075 (1972).

[2] R. SJöblom and J. Tegenfeldt, J. Magn. Reson. 20, 484 (1975).

[3] R. SJöblom and M. PunkKinen, J. Magn. Reson. 20, 491 (1975).

[4] R. SJöвlom, J. Magn. Reson. 22, 425 (1976).

[5] P.J. Haigh, P.C. Canepa, G.A. Matzkanin, and T.A. Scott, J. Chem. Phys. 48, 4234 (1968).

[6] R. IKeda, R. Kadel, A. Weiss, N. Ishida, and D. Nakamura, Ber. Bunsenges. Phys. Chem. 86, 685 (1982).

[7] B.V.S. Murthy, K.P. RAMesh, and J. Ramakrishna, phys. stat. sol. (a) 142, 219 (1994).

[8] B. Jagadeesh, P.K. Rajan, K. Venu, and V.S.S. Sastry, Solid State Commun. 86, 803 (1993).

[9] B. Jagadeesh, P.K. Rajan, K. Venu, and V.S.S. Sastry, J. Phys. Chem. Solids 54, 527 (1993).

[10] S. Sato, R. Ikeda, and D. NaKamura, Ber. Bunsenges. Phys. Chem. 86, 936 (1982).

[11] Y. FuRUKAWA and D. NAKAMURA, Z. Naturf. 44a, 1122 (1989).

[12] D. Vijayaraghavan and J. Ramakrishna, Spectrochim. Acta A 49, 1121 (1993).

[13] T.B. Brill and W.A. Welsh, J. Chem. Soc. Dalton Trans. 4, 357 (1973).

[14] J. BlazeJowski and J. SzYchlinski, Thermochim. Acta 36, 197 (1980).

[15] C.W. Gould and S.T. Gross, Ann. Chem. 25, 749 (1953).

[16] R.W.G. Wyckoff and R.B. CoReY, Amer. J. Sci. 18, 437 (1929).

[17] M. StammLeR, J. Inorg. Nucl. Chem. 29, 2203 (1967).

[18] L.K.E. NiemelÄ and J.E. HeiniLÄ, Chem. Phys. Lett. 82, 182 (1981).

[19] M.B. Dunn and C.A. McDowell, Mol. Phys. 24, 969 (1972).

[20] E.R. ANdRew and P.C. CANePa, J. Magn. Reson. 7, 429 (1972).

[21] Y. Furukawa, Y. Baba, M. Kaga, T. Asaji, R. Ikeda, and D. Nakamura, Z. Naturf. 46a, 809 (1991).

[22] S. Albert, H.S. Gutowsky, and J.A. RipMeester, J. Chem. Phys. 56, 3672 (1972).

[23] R.W. BERG, J. Chem. Phys. 71, 2531 (1979).

[24] R.W. Berg and I. Sotofte, Acta Chem. Scand. A32, 241 (1978).

[25] W. van der OHe, J. Chem. Phys. 62, 3933 (1975).

[26] W. van DER OHe, J. Chem. Phys. 63, 2949 (1975).

[27] L.S. Prabhumirashi, R. Ikeda, and D. NaKamura, Ber. Bunsenges. Phys. Chem. 85, 1142 (1981).

[28] R.W. Berg, Proc. 6th Internat. Conf. Raman Spectroscopy Ed. E.D. Schmid et al., Heyden, London 2, 382 (1978).

[29] A.G. Ludin and E.P. Zeer, Soviet Phys. - J. Exper. Theor. Phys. 21, 1032 (1965). 
